Diagnosis were made, definitions were clarified, and the nursing outcomes were identified based on the related factors, risk factors, and defining characteristics. After clarifying the challenges faced by the group/organisation, a diagnosis sheet was developed (figure 1).

Discussion The availability of this new sheet should encourage development of more systematised nursing diagnosis in occupational nursing, which is considered to be an urgent issue in Japan.

\section{THE STUDY OF COMPETENCY OF THE EMERGENCY FOR OCCUPATIONAL HEALTH NURSES}

${ }^{1} Y$ Matsuda*, ${ }^{2} \mathrm{M}$ Negishi, ${ }^{3} \mathrm{E}$ Furuhata, ${ }^{4} \mathrm{~K}$ Otani, ${ }^{5} \mathrm{E}$ Tomizawa, ${ }^{1,3} \mathrm{M}$ Arakida. 'International University of Health and Welfare Graduate School, Minato-ku Tokyo, Japan; ${ }^{2}$ Fujisawa Taxi Co., LTD., Fujisawa Kanagawa, Japan; ${ }^{3}$ International University of Health and Welfare, Odawara Kanagawa, Japan; ${ }^{4}$ Japanese Red Cross Toyota College of Nursing, Toyota Aichi, Japan; ${ }^{5}$ Sikoku University, Tokushima Tokushima, Japan

\subsection{6/oemed-2018-ICOHabstracts. 1006}

Introduction Emergencies care in occupational health care for organisations and groups and their individual departments and support for personal injuries and illnesses including life crises. However, the details of emergencies care in occupational health care are unclear. Therefore, the present study aimed to examine the competencies required of occupational health nurses (OHNs) in emergency care.

This study forms a part of efforts to construct a continuing education system for OHNs to improve their competencies in emergency care.

Methods A semi-guided interview was conducted with 10 OHNs. Referencing the data obtained from the research on continuing education for $\mathrm{OHN}$ s and the data obtained from the research on core curricula of nursing universities in Japan, these interview results were categorised base on their similarities and examined for their competencies in emergency care.

Results All participants in this study were women with 7-28 years of experience in occupational health nursing. The number of total employees at the workplace of each participant was assessed and it was established that for 2 of the participants there were $<300$ employees for each of their companies, for 1 of the participants there was 300-500 employees, for 3 other participants there were 500-1000 employees, for another 3 participants there were 1,000-3000 employees, and $\geq 10000$ for another one 1 of the participants. Items extracted from the results of the interviews included emergency treatment skills, motivation, preventive activities as well as team training and general employees education.

Conclusion The results suggested that to provide emergency care, OHNs must be able to identify life crises when they are occurring and provide emergency treatment, engage in preventive activities to prevent emergencies from occurring or aggravating, and exhibit ethical behaviour and professionalism in emergencies. Based on these details, we intend to further investigate the content of education and develop a continuing education program for OHNs.

\section{9 \\ A NATIONWIDE SURVEY ON THE CURRENT IMPLEMENTATION AND COMPETENCY OF OCCUPATIONAL HEALTH NURSES ON THE COLLABORATION WITH PUBLIC HEALTH SERVICES}

Yuko Mitsuhashi, Noriko Nishikido. Nursing School of Health Sciences, Tokai University

\subsection{6/oemed-2018-ICOHabstracts.1007}

Introduction We examined the current implementation and competency of occupational health nurses(OHNs) on the collaboration with public health services(PHS).

Methods A self-administered questionnaire was mailed to 2574 registered OHNs querying basic information, past PHS collaboration experience, direct PHS collaborative personnel, and competencies used in the collaboration. Our study was approved by the Ethics Committee, School of Health Sciences, Tokai University.

Results Of 815 recovered questionnaires (31.7\%), 806 were valid (31.3\%). Respondents' age group was most commonly 40-49 years (36.6\%). Mean total years of OHN experience was 14.7 years; 150 respondents $(18.6 \%)$ had public health nurse experience. Although 658 respondents (82.6\%) understood the necessity of the collaboration with PHS, only 285 (36.4\%) had PHS collaboration experience. Common collaborative partners were prefectural public health nurses(PHNs) (55.3\%) and PHNs who belong to cities and municipalities (52.5\%), suggesting OHNs collaborate with PHNs within the nursing field. The competency most commonly used by OHNs for general duties was including personal questions during interviews to establish a rapport so workers can discuss personal issues' (255 respondents, 90.4\%). The competency most commonly used in PHS collaboration was 'assisting workers in acquiring knowledge regarding problem-solving and utilising local resources' $(74.3 \%)$. Forty percent of respondents used a unique $\mathrm{OHN}$ competency, 'understanding that family members' health issues affect workers, and emphasising the need for support when relaying this to the personnel division'. Highly likely ( $\geq 80 \%$ validity) bases for PHS collaboration were 'open attitudes toward collaboration with professionals outside occupational health and nursing' and 'believing OHNs asking for outside help is normal when needed' in $77.4 \%$ and $73.5 \%$ of respondents, respectively.

Discussion Over $60 \%$ of OHNs did not collaborate with PHS despite understanding the necessity. Nurses who collaborated had unique competencies. Training for OHNs to acquire such competencies is necessary to ensure smooth PHS collaborations.

This study was funded by JSPS KAKENHI Grant Number 15 K11867 (Scientific Research C).

\section{OCCUPATIONAL HEALTH NURSING CHALLENGES IN DEVELOPING COUNTRIES: THE CASE OF ZIMBABWE}

F Moyo*. Midlands Occupational and Travel Health Centre, Gweru, Zimbabwe, Zimbabwe Occupational Health nurses, Harare, Zimbabwe

10.1136/oemed-2018-ICOHabstracts. 1008 